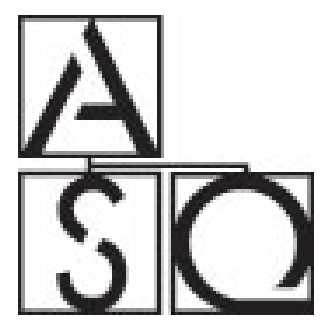

Single-Loop and Double-Loop Models in Research on Decision Making

Author(s): Chris Argyris

Source: Administrative Science Quarterly, Vol. 21, No. 3 (Sep., 1976), pp. 363-375

Published by: Johnson Graduate School of Management, Cornell University

Stable URL: http://www.jstor.org/stable/2391848

Accessed: 08/10/2008 15:21

Your use of the JSTOR archive indicates your acceptance of JSTOR's Terms and Conditions of Use, available at http://www.jstor.org/page/info/about/policies/terms.jsp. JSTOR's Terms and Conditions of Use provides, in part, that unless you have obtained prior permission, you may not download an entire issue of a journal or multiple copies of articles, and you may use content in the JSTOR archive only for your personal, non-commercial use.

Please contact the publisher regarding any further use of this work. Publisher contact information may be obtained at http://www.jstor.org/action/showPublisher?publisherCode=cjohn.

Each copy of any part of a JSTOR transmission must contain the same copyright notice that appears on the screen or printed page of such transmission.

JSTOR is a not-for-profit organization founded in 1995 to build trusted digital archives for scholarship. We work with the scholarly community to preserve their work and the materials they rely upon, and to build a common research platform that promotes the discovery and use of these resources. For more information about JSTOR, please contact support@jstor.org.

Johnson Graduate School of Management, Cornell University is collaborating with JSTOR to digitize, preserve and extend access to Administrative Science Quarterly. 
Single-Loop and

Double-Loop Models in

Research on Decision

Making

\section{Chris Argyris}

Some current research and theory on organizational decision making from the political science literature is examined, in which the potential role of learning and feedback in the decision-making process is largely ignored. An espoused theory of action based on single-loop learning is found to be the most general model of action. A double-loop model is proposed as providing feedback and more effective decision making.

\section{RESEARCH AND THE STATUS QUO}

Cohen and March (1974: 205) state explicitly: "First, we do not believe that any major new cleverness that would conspicuously alter the prevailing limits in our ability to change the course of history (in organizational theory and practice) will be discovered." However, a few pages later (Cohen and March, 1974: 215), in the fascinating section on "Technology of Foolishness," they raise questions about certain "robust faiths" that have become segments of contemporary Western civilization, such as the concept of choice, which assumes pre-existence of purpose, the necessity of consistency, and the primacy of rationality. Their questions seem to imply that the course of history may be alterable, and it is not surprising that this inconsistency appears in a section in which Cohen and March attempt to apply their framework to develop practical advice to administration.

The problem has two aspects. The first is that Cohen and March recommend a leadership strategy that has been called (by March) mini-Machiavellian and derivable from the major properties of decision making in organized anarchies that Cohen and March found as a result of their research. They recommended that the leader should (1) be involved in the organization in order to provide the energy needed to influence major decisions, (2) become informed so that in an information poor system (characteristic of organized anarchies) he will then become valued, (3) persist in promoting his views, since a decision defeated today may be accepted tomorrow, (4) exchange status for substance, (5) facilitate opposing factors to participate, and (6) overload the system thereby making themselves more necessary.

This advice appears to be a framework for maintaining organizations as Cohen and March found them: mini-Machiavellian and organized anarchies. The advice could also perpetuate the expectations of subordinates, especially the ineffective and/or less involved ones, that organizations and their leadership will never change, and can lead to physical and psychological exhaustion in leaders. Imagine being advised to work hard, to be present at most meetings, to provide energy in a system whose participants refuse to energize (and through their bickering are capable of using up any energy input), and to facilitate opposition because it is the best way to correct excesses or polarizations of positions.

Finally, the advice appears to sanction deceit. The effectiveness of a mini-Machiavellian leadership is based on the assumption that the reasons for behavior or strategy are kept secret. For example, Cohen and March (1974: 211) recommend that if the president of a university wants to untangle a 
curriculum reform from an issue of social justice, he should create a garbage can attractive enough to seduce the social justice proponents away from the immediate action.

To those familiar with organizational activity, Cohen and March have elevated leadership strategy to what some would consider dysfunctions in organizations.

Cohen and March might object to calling the strategy dysfunctional, since they described organizations as they were and since they provided a section on the technology of foolishness which raised some basic questions about orthodoxy in decision making. The term, foolishness, indicates that Cohen and March were aware how radical their questions would appear to many theorists on decision making. What Cohen and March reported was a rational theory of leadership, consistent with their model, which, in turn, was consistent with the organizations they studied.

In examining other literature, to learn what can be done about this problem, one finds mostly conjectures and almost no empirical research. The primary objective stated in almost all of the studies is to attempt a rigorous description of the problem. This position is predictable because the underlying assumption of much research in social science is to conduct rigorous research about conditions, systems, relationships, and so forth as they are (Argyris, 1968, 1971, 1973, 1974, 1975; Hackman and Morris, 1975). Such an assumption is considered in that useful insights for correcting problems can be derived from the accurate description of a problem.

A paradoxical assumption is that change is possible even though the factors causing the problems are taken as given. For example, Cohen and March (1974) view intergroup coalition rivalries, avoidance of uncertainty, interpersonal threat, and mistrust as factors inhibiting decision-making effectiveness; but they were viewed as factors to be understood, not altered. This does not mean that suggestions are not made in the literature to increase decision-making effectiveness. For example, a collegial style of decision making might be recommended, but no insight provided on this could be attained without first reducing conflict, mistrust, and so on.

\section{ALTERNATIVE VIEWS}

An earlier model called "synoptic" described a decision maker going through a set of processes where he or she (1) identified and systematically ordered objectives and values, (2) comprehensively surveyed all possible means of achieving those values, (3) exhaustively examined the sequences, and (4) made a choice that maximized or reached some acceptable level of achievement. Lindblom (1959, 1965: 137-138, 1968) described this model, but with other researchers argued that this view was not adapted to man's limited intellectual capacities, to the inadequacy of information, to the high cost of analysis, to learning from failures, or to the close relationship between fact and value in policy making. Consequently they proposed a third model described as an incremental approach to decision making (Pressman and Wildavsky, 1973; Moynihan, 1972). Researchers proposing this model consider analysis to be drastically limited and the definition of a good policy arbitrary, and it is probably not possible 


\section{Single-Loop and Double-Loop}

to select rigorous criteria for effectiveness. The closest one could come to understanding effectiveness would be to define key questions, which, if answered, would make it possible to evaluate effectiveness. Effective action is more a succession of comparisons between actions and feedback from the environment, which provide information for the next action or decision. Since decisions are made on necessarily incomplete information, once executed, feedback is required to evaluate their effectiveness.

It is not the purpose here to argue for any of these approaches, but rather to explore the importance that learning processes play in problem solving and decision making. The effectiveness of this approach depends upon being able to subdivide problems and upon the actions being repeatable enough so that decision makers can learn from their actions and adapt their decision making and behavior accordingly; also upon the availability of valid information from the environment within realistic time constraints to make corrections possible.

\section{Underlying Role of Learning in Decision Making}

Learning is here defined as the detection and correction of errors, and error as any feature of knowledge or of knowing that makes action ineffective. Error is a mismatch: a condition of learning, and matching a second condition of learning. The detection and correction of error produces learning and the lack of either or both inhibits learning.

It is difficult to conceive of how decision-making processes that include such activities as search, design, and choice could operate effectively without valid information. It is here assumed that the more complex and ill-structured a problem, the higher the probability of ambiguity and so the higher the probability of errors; that is, the lower the probability that actions will match plans effectively. Furthermore, problems become increasingly complex and ill-structured, the need for learning increases, but so does the difficulty in carrying out effective learning.

An assumption in the three models of decision-making processes just described is that complex decisions can be subdivided and the subordinate problems solved in some sort of functional sequence. Such an approach would be especially appropriate for decisions that once made are not intended to be altered. This makes crucial the learning processes before the decision. For example, Allison (1971), George (1973), and Neustadt (1970) provide illustrations of decisions where the learning could have occurred before the decisions were made, though in many cases, it did not.

\section{Factors That Inhibit Learning}

At least two important sets of variables can be altered to increase the effectiveness of learning, no matter at what point the learning is to occur. One is the degree to which interpersonal, group, intergroup, and bureaucratic factors produce valid information for the decision makers to use to monitor the effectiveness of their decisions. The other is the receptivity to corrective feedback of the decision-making unit-that is, individual, group, or organization. 
Allison (1971) presented evidence that organizational and bureaucratic political factors significantly influenced the amount and quality of the learning during decision making. Examples of organizational factors are partial resolutions of interdepartmental and interpersonal conflicts, ineffective and incomplete search, avoidance of uncertainty, political exchanges, and annexation of other units. Examples of bureaucratic and political factors among individuals are competitive games; bargaining, parochial priorities, personal goals, interests, stakes, and stands; use of power; misperception, and miscommunication.

Halperin (1974: 235-279) suggested that there were "maneuvers" to affect the information given and received; for example, (1) reporting only those factors that support one's view, (2) biasing reports to senior participants to promote one's own view, (3) not reporting facts that indicate danger, and (4) avoiding senior officers who might report facts that one wished to suppress.

Hoopes (1969) described the distortion and manipulation of information by subordinates and the lack of open debate. Wildavsky (1964) and Wildavsky and Pressman (1974) focused especially on the competitiveness and bureaucratic win-lose politics among bureaus and departments. Thomson (1968) and Halberstam (1969) provided vivid examples of how personal ideologies, cognitive rigidities, and concepts of loyalty inhibited the generation and communication of valid information to upper levels. Geyelin (1966) and Halberstam (1969) provided evidence that key officials repeatedly and privately attributed motives to others, which then influenced the information that the officials gave or expected to receive. Schlesinger (1973) and Sorenson (1963) stated that secrecy had been a governing principle of presidential decision making nationally, and that conflict was the "one quality which characterizes most issues likely to be brought to the President." Moynihan (1972) suggested that bureaucratic political strife and competitiveness led to "competitive depreciation." Wildavsky (1964) provided informative descriptions of the political warfare, one-upmanship, and power maneuverings that occurred during budgetary processes. Donavan (1970: 32,33 ) described how the decision related to the Bay of Pigs moved to execution without President Kennedy being able either to control or to reverse it, and how President Johnson was misled into signing community-action legislation that provided for citizen participation, a concept which he did not like. Gawthrop (1971) described administrative politics as games in which the basic rules were to maximize winning and self-interest. Schlesinger (1973) described the compelling need, especially of the President, for "passports to reality" ' since the world that immediately surrounds superiors is so often unreal. Neustadt's $(1960,1970)$ work presaged many of the observations above and suggested that key top figures seem to forget the constraints others have placed upon them by their national governance processes as well as by deeply held norms developed over years of national political activity.

Moreover, the literature suggests that the factors that inhibit valid feedback tend to become increasingly more operative as the decisions become more important and as they become 


\section{Single-Loop and Double-Loop}

more threatening to participants in the decision-making processes; that is, valid information appears to be more easily generated for less important and less threatening decisions. This is a basic organizational problem for it is found not only in governmental organizations, but also in business organizations, schools, religious groups, trade unions, hospitals, and so on (Argyris, 1964, 1970, 1972).

One might say that participants in organizations are encouraged to learn to perform as long as the learning does not question the fundamental design, goals, and activities of their organizations. This learning may be called single-loop learning. In double-loop learning, a participant would be able to ask questions about changing fundamental aspects of the organization (Allison, Neustadt, Halperin, and others).

Furthermore, most groups and organizations studied in their usual settings permit only single-loop learning. Recent research on individual adult learning suggests that human beings are also acculturated to be primarily single-loop learners in dealing with other human beings and with substantive, controversial issues (Argyris and Schon, 1974). This high degree of consonance between learning acculturation and the kind of limitations placed on learning within groups and organizations results in processes that limit exploration and information and so help provide stability but also inhibit learning in fundamental organizational issues.

To intervene in these circular processes, one needs a model that helps to explain what aspects of current behavior of decision makers and policy makers inhibit double-loop learning, a model that would increase the effectiveness of decision making and policy making, and finally one that would make it possible to use the explanatory model to achieve effectiveness.

\section{THEORIES OF ACTION}

Argyris and Schon (1974) stated that all human action was based on theories of action. One can differentiate between espoused theories of action and theories-in-use. Espoused theories of action are those that people report as a basis for actions. Theories-in-use are the theories of action inferred from how people actually behave (taken from video or audio tapes, or other instruments that focus on collecting relatively directly observable behavior). Most individuals studied seem to be able to detect the discrepancies between their espoused theories and theories-in-use of others, but were not able to detect similar discrepancies in themselves. People observe the discrepancies manifested by others but they are programmed with theories-in-use that say, "If you observe others behaving incongruently with what they espouse, in the name of effectiveness, concern, diplomacy, do not tell them."

\section{Single-Loop Model}

A model of the theory-in-use was found to account for much of the behavior relevant to this study (Argyris and Schon, 1974). It was hypothesized that human behavior, in any situation, represents the most satisfactory solution people can find consistent with their governing values or variables, such as achieving a purpose as others define it, winning, suppressing negative feelings, and emphasizing rationality. 
It was also hypothesized that human beings learned to associate behavioral strategies with their governing values or variables. The primary strategies are to control the relevant environment and tasks unilaterally and to protect themselves and their group unilaterally. The underlying behavioral strategy is control over others, although people vary widely in how they control others. Giving the meaning of a concept to others and defining its validity for them is one of the most powerful ways to control others.

Control as a behavioral strategy influences the leader, others, and the environment in that it tends to produce defensiveness and closedness, because unilateral control does not tend to produce valid feedback. Moreover, controlling behavior unilaterally may be seen by others as defensiveness. Groups composed of individuals using such strategies will tend to create defensive group dynamics, reduce the production of valid information, and reduce free choice. Consequently it was hypothesized that a particular kind and quality of learning would take place. There would be relatively little public testing of ideas, especially important or threatening ones. As a result, leaders would tend to receive little genuine feedback and others would tend not to violate their governing values and so disturb the accepted fundamental framework. Many of the hypotheses or hunches that the leaders generate would then tend to become limited and accepted with little opposition. Moreover, whatever a leader learned would tend to be within the confines of what was acceptable.

Under these conditions, problem solving about technical or interpersonal issues would be rather ineffective. Effective problem solving occurs to the extent individuals are aware of the major variables relevant to their problem and solve the problem in such a way that it remains solved (at least until the external variables change); and, moreover, that they accomplish these without reducing the current level of problem-solving effectiveness (Argyris, 1970). Under these conditions, top administrators tend to become frustrated with the ineffectiveness of the decision-making process and react by striving to increase control, by increasing secrecy about their own strategies, and by demanding loyalty of subordinates that borders on complete agreement with their views.

Besides the acculturation of individuals to these interpersonal group and intergroup dynamics, the consequences just described would be compounded by pyramidal structures, management information systems, including budgets (Argyris, $1964,1965)$. In other words, the activities documented in the literature cited above exist at the individual, interpersonal, group, intergroup, organizational, and intraorganizational level in such a way that they mutually reinforce each other to create a stable, indeed, an ultra stable slate (Schon, 1972).

\section{Double-Loop Model}

A model incorporating double-loop learning can avoid the consequences of a model based on single-loop learning (Argyris and Schon, 1974). The governing variables or values of Model II are not the opposite of Model I. The governing variables are valid information, free and informed choice, and internal commitment. The behavior required to satisfice these 


\section{Single-Loop and Double-Loop}

values also is not the opposite of Model I. For example, Model I emphasizes that the individuals are expected to be articulate about their purposes, goals, and so forth, and simultaneously control the others and the environment in order to ensure achievement of their goals. However, in the doubleloop model, the unilateral control that usually accompanies advocacy is rejected because the typical purpose of advocacy is to win; and so, articulateness and advocacy are coupled with an invitation to confront one another's views and to alter them, in order to produce the position that is based on the most complete valid information possible and to which participants can become internally committed. This means that the leader must be skilled in eliciting double-loop learning. Every significant action in the double-loop model is evaluated in terms of the degree it helps the participants generate valid and useful information, including relevant feelings, and solve the problem so that it remains solved without reducing the level of problem-solving effectiveness.

The behavioral strategies of this model involve sharing power with anyone who has competence, and with anyone who is relevant in deciding or implementing the action, in the definition of the task, or the control over the environment. Face saving is resisted because it is seen as a defensive nonlearning activity, and any face-saving action that must be taken is planned jointly with the people involved, with the exception of individuals vulnerable to such candid and joint solutions.

Under these conditions individuals would not tend to compete to make decisions for others or to outdo others for self-gratification. They would try to find the most competent people for the decision to be made, and would try to build viable decision-making networks in which the major function of the group would be to maximize the contributions of each member so that when a synthesis was developed, the widest possible exploration of views would have taken place.

Finally, if new concepts were formulated, the meaning given to them by the formulator and the inference processes used to develop them would be open to scrutiny by those who were expected to use them. Evaluations and attributions would be the result of directly observable data after the concepts were used. Also, the formulator would feel responsible to present the evaluations and attributions so as to encourage open and constructive confrontations.

If the governing values and behavioral strategies just outlined are used, then the degree of defensiveness in individuals, within, between, and among groups, would tend to decrease and free choice would tend to increase, as would feelings of commitment. The end result should be increased effectiveness in decision making or policy making in the monitoring of the decisions and policies and in the probabilities that errors and failures would be communicated openly and that actors would learn from the feedback.

\section{TRANSITIONAL MODEL}

It is not easy to conceptualize models of transition from a single-loop to a double-loop model that do not violate the requirements of the latter. Moreover, if one is able to design 
such processes, the probability of being able to test them empirically is low. Few subjects are interested in genuinely new options, especially if learning them may be difficult and if having learned them there is little support from subordinates' peers, and superiors, as well as from organizational policies and practices to use the new skills.

Learning to become aware of one's present theory-in-use and then altering it is a very difficult process, because it requires that individuals question the theories of action that have formed the framework for their actions. Learning about double-loop learning through lectures, reading, and case discussions will lead to learning at the espoused level rather than at the level of theory-in-use.

For example, the single-loop model teaches individuals to be high on articulate advocacy and simultaneously high on unilateral control over others in order to win. Governmental and private executives can be taught to be articulate advocates in such a way that control is shared in order to increase time for study, and the executives might even come to value the new behavior highly, yet they are unable to behave according to the new requirements, or to experience the appropriate feelings. In the single-loop model inquiry may be seen as weakness; in the double-loop model, it is seen as strength.

Another difficulty is that in organizations, human beings are acculturated to accept a role in a pervasive atmosphere of deception. For example, A would not tell $B$ that he or she was about to act destructively toward $B$; $C$ would not tell $D$ that he or she was distorting information to $D$; and $E$ would not tell $F$ that he or she was flattering $F$. Yet all six know that they and others act in such ways, and that the accepted behavior is to act as if no one knows that such activities go on.

Second, if theories-in-use are the basis of behavior, then they represent a source of confidence that one has in functioning effectively in one's world. To change one's theory-in-use would be risky. There are few group, organizational, or societal supports for significantly different behaviors. New behavior, for example, a focus on real-time inquiry and shared power and trust, could actually cause difficulties for a person because it would be considered deviant behavior. New behavior could also harm the individual because others might use the new power and the trust against him or her.

Third, changing to a double-loop model involves exploration of certain basic values and feelings. For example, if an individual decides to explore reducing his unilateral control over others, he will soon confront himself with the question, why does he control others? Typically, he may respond by saying that if he did not control others, he could not get things done. "People respect what I inspect." All this is confirmable in a Model I world.

In exploring new behaviors some top officials have checked their hypotheses about their lack of confidence with their subordinates. To their dismay they have learned that their subordinates felt the officials' mistrust, and that they kept this knowledge hidden just as the officials were keeping their attributions of mistrust of the subordinates hidden. Also the subordinates could give officials valid reasons for behaving in 


\section{Single-Loop and Double-Loop}

ways that required the officials' control. In short, the officials learned that much of their sense of a need for unilateral control was a self-fulfilling prophecy (Argyris 1976a).

Such experiences help one to understand why people accustomed to single-loop learning find it difficult to change. For example, many "alternative schools" were started because certain teachers and students were against the Model I schools. A major strategy of alternative schools included going from a highly structured to a very loose school; from unilateral control by teachers to complete equality with students; from teachers evaluating students to students evaluating teachers. These strategies did not work for two reasons. One cannot have effective school organizations without structure with complete equality, and without evaluations of performance of students. Moreover, when one examines carefully the actual behavior of the teachers and the students, it went from the opposite of Model I to an oscillatina Model I (Aravris 1974). The same analysis appears to be relevant to the experiments for community participation projects. Many floundered between the competitive win-lose tactics of militant minorities to the opposite role of withdrawal of power and structure related to such learning experiences as T-groups or sensitivity training. A large portion of T-group practice (not theory) is based on a model that is the opposite to the single-loop model; that is, one characterized by withdrawal and passivity. Such a model is not apt to produce more effective decision making; it may actually produce an increase in participant narcissism and, therefore, increased problems when the participant strives to behave with others who have not been in his or her T-groups (Argyris, 1972).

Such data raise questions about two commonly held assumptions by researchers in this field. The first assumption is that changes can be produced directly frorn descriptive research. Bauer (1974), for example, suggested that there is a continuous relationship from understanding a given situation, to designing a new one and then realizing it. Research tends to suggest that change based on the double-loop model would require a shift in the behavior of individuals and in group, intergroup, and organizational processes.

The second assumption is that changes to make the environment approximate the requirements of the double-loop model would lead to behavior and values appropriate to the model. This assumption is not predicted by the theory, which states that no changes will occur toward a double-loop model unless the individuals change their current theories-in-use. This also means that changes in organizational structure, management information systems, and organizational norms will not lead directly to changes in behavior of the people within the new system.

\section{MULTIPLE ADVOCACY MODEL}

George (1972) showed that it is possible for researchers to develop normative prescriptive models that are systematic and empirically testable. He (1972: 758) hypothesized that a system of multiple advocacy worked best and was likely to produce better decisions when three conditions were satisfied: 
(1) no major maldistribution of power, weight, influence, competence, information, or analytical resources; (2) bargaining and persuasive skills among members, participation of chief executives to monitor and regulate the workings of multiple advocacy; and (3) time for adequate debate and exchange of ideas.

On the basis of espoused theories and theories-in-use, however, if for example, power, weight, and influence are functions of a role, then maldistribution of such variables would be alterable by order of the chief executive. However, the theories-in-use of individual members also influence their power, weight, and influence in groups. In studies (Argyris, 1969) of nearly 300 policy-making and decision-making sessions in the government and private sectors, such theory-inuse variables made significant differences in the effectiveness of individual members and in the quality of the decisions. However, the variables were rarely, if ever, discussed openly because such discussions violated the governing values of suppressing threatening issues and the negative feelings against the norms against interpersonal risk taking. Questions can also be raised about bargaining and persuasive skills. In a single-loop model, such skills are closely correlated with unilateral control and manipulation of information, secrecy, and so on, which inhibit the kind of discussion required in multiple advocacy if it is to be effective.

Analysis of tapes (Argyris, 1969) of policy-making and decision-making meetings suggests that groups rarely have enough time for adequate debate partially because the winlose dynamics coupled with single-loop learning and the emphasis on control of others make discussions competitive. Consequently, if the theories-in-use of groups inhibit effective discussion, how effective can the chief executive be in monitoring such factors? George (1972: 761) stated that the multiple advocacy required that the chief executive define his or her own role as that of a magistrate who evaluates, judges, and chooses among the various policies proposed by advocates. Some research (Argyris, 1956, 1968, 1974; Blake and Mouton, 1968) would indicate that this would tend to magnify the win-lose dynamics and/or create a greater sense of hidden conformity.

George suggested that with the introduction of the magistrate role, the advocates will no longer compete against each other but they will compete for the magistrate's attention. Our research would raise some doubts because some of the key variables that influence the magistrate's attention are related to the effectiveness with which the members compete with each other. George may wish that the individuals carrying out the custodian role focus on reducing the competitiveness that is destructive. But there is nothing in George's model to suggest that presently such behavior would be seen, by the participants, as deviant and odd. Also, if our research to date is valid, there are few top administrators who hold such skills.

George also suggests that collegial decision making coupled with the three conditions mentioned would increase the effectiveness of decision making. The path to increased effectiveness may be more difficult. Several decades ago execu- 


\section{Single-Loop and Double-Loop}

tives in government and private industry associated with the production of complex electronic equipment developed what they called product planning groups, task forces, and matrix organizations. The idea was congruent with the one espoused by George. If one could bring together competent people, with adequate resources and time, and with relatively equal weight of power and influence, more effective decisions should be made. A study of nine such teams in matrix organizations showed that as time progressed the participants, through their behavior (theory-in-use), altered these groups to look more like little pyramidal organizations with little genuine collegial style (Argyris, 1967).

Finally, George identified nine possible malfunctions of policy making that could not be ignored, no matter what model of decision making was used. These included: (1) the chief executive and his other advisors agree too readily on the kind of problem and on a response to it; (2) disagreements do not cover the full range of relevant hypotheses and options; (3) there is no advocate for an unpopular policy action, and so on. These malfunctions were confirmed by other research (Janis, 1972).

George's case for multiple advocacy, with which this writer agrees, points up some important gaps that can begin to be reduced by examining literature and by pursuing further empirical research. The gaps become evident when the distinction is made between espoused theory and theory-in-use. The latter type of data is necessary for the empirical test of any model as well as for knowledge that will be helpful in practice, but these data are still lacking.

\section{DISCUSSION AND SUMMARY}

It is acknowledged that the research on the two models is only beginning, although from the data available so far, one can conclude that many espouse the double-loop model or some combination of both models. The data on theory-inuse indicate that most behavior may be categorized as approximately the single-loop model.

One difficulty with these results is that they may be based on research in which the categories are poorly defined. A more differentiated conceptual scheme might produce different results. The results of studies so far range from high interobserver reliability to studies where the subjects scored their own behavior and judged it to approximate the single-loop model, even though they had originally claimed it to be double-looped (Argyris, 1976c). Finally, predictions on the basis of the present conceptual scheme were confirmed (Argyris and Schon, 1974).

Double-loop learning can occur under the conditions of the single-loop model under extreme crisis or revolution. Unfortunately, there are no directly observable data, such as tape recordings, that could lead to inferences if the changes in behavior were those of the double-loop model. Under such extreme conditions, members can be brutally candid, discount the negative impact upon them from such behavior on the grounds that the stakes are very high and the members' motives are sincere; that is, they are not capable of more effective behavior, yet the need for honesty is greater than 
the need to avoid hurt feelings (Janis). An excellent example of this state in the deliberations of the Marshall Plan is where Kennan felt so punished that he left the meeting to cry and regain his composure (Janis, 1972).

This mode of behavior depends upon having members who can tolerate competitiveness in the group, but this may exclude individuals who may have substantive contributions to make, but cannot tolerate severe competition. Groups composed of highly competitive people also tend to create norms that make other groups "outsiders" and "competitors" if not enemies (Janis, 1972). Moreover, participants from other groups coming into these groups in order to give reports, tend to feel intimidated and then presentations tend to be less effective, which may be viewed by the competitive group as evidence of their superiority. In short, the presentation may be pessimistic and there may be more individuals, groups, and organizations falling into the double-loop model, implied by our admittedly incomplete research; but further empirical research is needed to make the case convincing. Such research would have to obtain directly observable data (for instance, transcripts) and not remain at the espoused level (questionnaires and reports). Another way of interpreting the findings is that they illustrate the scope and depth of the problem and help to explain why much research in social science tends to support the status quo.

Chris Argyris is James Bryant Conant Professor of Education and Organization Behavior, Graduate School of Education, Harvard University.

\section{REFERENCES}

Alderfer, Clayton P., and L. Dave Brown

Learning from Changing. Beverly Hills, Calif.: Sage Publications, in press.

Allison, Graham T.

1971 Essence of Decision: Explaining the Cuban Missile Crisis. Boston, Mass.: Little Brown.

Argyris, Chris

1965 Organization and Innovation. Homewood, III.: Irwin-Dorsey.

1966 Some Causes of Organizational Ineffectiveness within the Dept. of State, Center for International Systems Research, Occasional Paper, No. $\rightarrow$ 2.

1967 "Today's problems with tomorrow's organizations." Journal of Management Studies, 4: 31-55.

1969 "The incompleteness of social psychology theory." American Psychologist, 24: 893-908.

1970 Intervention Theory and Method. Reading, Mass.: Addison-Wesley.

1971 Management and Organizational Development. New York: McGraw Hill.
1972 "Do personal growth laboratories represent an alternative culture?" Journal of Applied Behavioral Science, 8: 7-28.

1973 On Organizations of the Future. Albert Schweitzer Lecture given at Syracuse University on May 11, 1972. Published as Sage Professional Paper in Administration and Policy Studies \#03-006.

1973 The CEO's Behavior: Key to Organizational Development, Harvard Business Review, March-April, Vol. 51, No. 2: 55-64.

1973 "Some limits of rational man organizational theory." Public Administration Review, 33: 253-267.

1974 "Alternative schools: a behavioral analysis." Teachers College Record, 75: 429-452.

1975 "Some dangers in applying results from experimental social psychology." American Psychologist, 30: 469-485.

1976a Increasing Leadership Effectiveness. New York: InterScience, John Wiley. 1976b "Problems and new directions for industrial psychology." In Marvin Dunnette, ed., Handbook of Industrial and Organizational Psychology. Chicago: Rand-McNally.

$1976 c$ "Theories of action that inhibit individual learning." American Psychologist, in press.

Bauer, Raymond A.

1974 The Convergence of What Is and What Should Be. Division of Research, Harvard Business School HBS-7.

Blake, Robert R., and Jane Mouton 1968 Corporate Excellence through Good Organizational Development, Houston, Texas: Gulf Publishing Co.

Cohen, Michael D., and James G. March

1974 Leadership and Ambiguity, The American College President. New York: McGraw Hill Book Co.

Cyert, Richard M., and James G.

March

1963 A Behavioral Theory of the Firm. Englewood Cliffs, N.J., Prentice-Hall. 


\section{Single-Loop and Double-Loop}

Donovan, John C.

1970 The Policy Makers. Indianapolis, In.: PegasusWestern Publishers.

Gawthrop, Louis

1971 Administrative Politics and Social Change. New York: St. Martin's Press.

George, Alexander

1973 "The case for multiple advocacy in making foreign policy." American Political Science Review, LXVI: 751-785

Geyelin, Philip

1966 Lyndon B. Johnson and the World. New York: Frederick A. Praeger.

Golembiewski, R. T.

1972 Renewing Organizations. Itasca, III.: F. E. Peacock.

Hackman, J. Richard, and C. G. Morris

1975 "Group tasks, group interaction process, and group performance effectiveness - a review and proposed integration." In L. Berkowitz (ed.), Advances in Experimental Social Psychology, Vol. 8, N.Y. Academic Press.

Halberstam, David

1974 The Best and the Brightest. New York: Random House.

Halperin, Morton $\mathrm{H}$.

1974 Bureaucratic Politics and Foreign Policy. Washington, D.C.: The Brookings Institution.

Janis, Irving L.

1972 Victims of Groupthink. Boston: Houghton Mifflin.
Katz, Daniel, and Robert L. Kahn

1966 The Social Psychology of Organizations. New York: John Wiley.

Lawrence, Paul R., and Jay W.

Lorsch

1967 Organization and Environment Managing Differentiation and Integration. Boston: Division of Research, Harvard University, Graduate School of Business Administration.

\section{Likert, Rensis}

1961 The Human Organization. New York: McGraw Hill.

Lindblom, Charles E.

1959 "The science of 'muddling through.' "Public Administration Review, XIX: 79-88.

1965 The Intelligence of Democracy: Decision Making through Mutual Adjustment. New York: The Free Press.

1968 The Policy Making Process Englewood Cliffs, N.J.: Prentice-Hall.

Marrow, A. J., D. G. Bowers, and S. E. Seashore

1967 Management by Participation. New York: Harper and Row.

Moynihan, Daniel P.

1972 Coping. New York: Random House.

Neustadt, Richard E.

1960 Presidential Power: The Politics of Leadership. New York: Wiley.

1970 Alliance Politics. New York: Columbia University Press.
Porter, Lyman W., E. E. Lawler, and J. R. Hackman

1975 Behavior in Organizations. New York: McGraw Hill.

Pressman, Jeffrey L., and Aaron Wildavsky

1973 Implementation. Berkeley, Calif.: University of California Press.

Schein, Edgar

1965 Organizational Psychology. Englewood Cliffs, N.J., Prentice-Hall.

Schlesinger, Arthur M. Jr.

1973 The Imperial Presidency. Boston: Houghton Mifflin.

Schon, Donald

1971 Beyond the Stable State. New York: Random House.

Simon, Herbert A.

1970 The Sciences of the Artificial. Cambridge, Mass.: M.I.T.

Sofer, Cyril

1961 The Organization from Within London: Tavistock Publications.

Steinbruner, John D.

1974 The Cybernetic Theory of Decision. Princeton, N.J.: Princeton University Press.

Thomson, James C., Jr.

1968 "How could Vietnam happen?" The Atlantic, pp. 47-53.

Wildavsky, Aaron

1964 The Politics of the Budgetary Process. Boston: Little Brown. 